ФИЛОНЕНКО Виктор Иванович - доктор социологических наук, профессор Института философии и социально-политических наук, директор Центра социально-политических исследований Южного федерального университета (344065, Россия, г. Ростов-на-Дону, пер. Днепровский, 116, корп. 3, каб. 131; vfilonenko@sfedu.ru)

МОСИЕНКО Ольга Сергеевна - кандидат социологических наук, старший преподаватель Института социологии и регионоведения Южного федерального университета (344006, Россия, 2. Ростов-на-Дону, ул. Пушкинская, 160; mosienko.olga@таil.ru)

МАГРАНОВ Алексей Сергеевич - кандидат социологических наук, старший научный сотрудник Центра социально-политических исследований Южного федерального университета (344065, Россия, г. Ростов-на-Дону, пер. Днепровский, 116, корп. 3, каб. 136; alex_daredevil@таil.ru)

\title{
РОЛЬ ШКОЛЫ В ФОРМИРОВАНИИ ГРАЖДАНСКОЙ АКТИВНОСТИ СТУДЕНЧЕСКОЙ МОЛОДЕЖИ ВУЗОВ ДОНА
}

\begin{abstract}
Аннотация. В статье проводится анализ гражданской и социальной активности молодежи. Авторы выделяют значение гражданской позиции в структуре социальной идентичности и отношение к соблюдению законов и вероятности совершения правонарушений у студенческой молодежи вузов Ростовской области в зависимости от типа оконченной школы. Статья основана на результатах мониторингового социологического исследования, реализованного в 2016 г. Авторы проводят сравнительный анализ с данными исследований 2006 и 2011 гг. по аналогичной программе с целью рассмотрения динамики показателей гражданской и социальной активности студенчества.
\end{abstract}

Ключевые слова: школа, гражданская активность, социальная активность, гражданская идентичность, студенческая молодежь, социализация

$\mathrm{O}$ дним из ведущих факторов формирования гражданской активности молодежи является школьная образовательная среда, в которой каждый обучающийся имеет одинаковые со всеми возможности для осуществления своих потенциальных потребностей и проявления активности в социальной и общественной жизни.

В 2016 г. Центр социально-политических исследований Южного федерального университета провел мониторинговое межрегиональное социологическое исследование «Противоречия и парадоксы социализации студенческой молодежи в условиях транзитивности современного российского общества». Общая выборка составила 4387 студентов 23 вузов и филиалов вузов Ростовской обл. и других регионов России: Краснодарского и Ставропольского краев, Волгоградской и Свердловской обл., Адыгеи, Калмыкии, Татарстана [Филоненко и др. 2017]. Выборочная совокупность в 13 вузах Ростовской обл. составила 2195 студентов очной формы обучения (1-5 курсы, а также магистры 1-го и 2-го года обучения). В 2006 и 2011 гг. в вузах Донского края были реализованы социологические исследования «Социализация и воспитание студенческой молодежи вузов Ростовской области» (выборка составила 2723 респондента в 2006 г. и 4029 респондентов в 2011 г.) [Социализация... 2014]. Данные проекты были выполнены с использованием аналогичных исследовательских программ, что позволяет провести сравнительный анализ и представить основные тенденции в динамике за 10-летний период.

В процессе реализации сравнительного анализа результатов мониторинговых социологических исследований проблем и парадоксов социализации студенческой молодежи вузов Ростовской обл. в зависимости от типа учебного заведения, дающего общее среднее или начальное/среднее профессиональное 
образование, мы выявили некоторые общие тенденции социокультурной среды современных университетов ${ }^{1}$.

Тенденция первая. На протяжении всех 3 этапов мониторинга в ведущих университетах подтвердилось преобладание парентократической (родительской) модели, в которой образование детей в большей степени обусловлено благосостоянием и желанием самих родителей, а не их личными способностями и стараниями. Если в 2006 и 2011 гг. около четверти респондентов поступили в вузы региона после окончания школы нового типа, то в 2016 г. этот показатель составил уже $31,7 \%$. А в ДГТУ число таких студентов достигло отметки в 48,3\%, в РостГМУ - 42,5\%, в ЮФУ - 36,3\%. Установлено, что школы нового типа и определенного профиля по многим каналам взаимосвязаны с базовыми высшими учебными заведениями. Как следствие, преимуществом при поступлении и обучении обладают те молодые люди, которые проживали в городах или рядом с ними и родители которых способны оплатить данные образовательные услуги. Для сравнения приведем данные по этому критерию в менее элитных университетах Дона: ЮРГПУ (НПИ) - 16,2\%, ДонГАУ - 18,7\%, АЧИИ - филиал ДонГАУ - $13 \%$.

Тендениия вторая. Итоги нашего исследования подтвердили общеизвестный факт: «образование есть удел образованных». Суть этого «удела» заключается в том, что, чем оно выше и качественнее, тем более «разбужены» образовательные потребности и тем чаще люди прибегают к учебе [Тощенко 2011: 74]. Прямая корреляция переменных с образованием родителей и категориями школ позволила установить, что в школах нового типа обучались $64 \%$ респондентов, отцы которых имели высшее образование, тогда как в традиционных школах таковых оказалось 46,9\%. Показательно, что в лицеях, гимназиях и профильных школах в 2016 г. обучались 41,2\% детей, чьи отцы являются руководителями предприятий и учреждений (рост на 7,4\% по отношению к данным 2006 г.), 37,7\% детей руководителей структурных подразделений (рост на 12,2\%), 34,7\% детей предпринимателей и коммерсантов (рост на 12,7\%).

Тенденция третья - это устойчивый рост численности студентов, проживающих до поступления в вуз в крупных, средних и малых городах. В 2016 г. горожане составили 70,1\% общего контингента студентов государственных университетов, представители села - 27,7\%. 54,7\% выпускников школ нового типа и определенного профиля областного центра, 30,3\% выпускников из других городов и лишь $11,9 \%$ из сельской местности стали учащимися высших учебных заведений. И здесь надо еще раз подчеркнуть, что основополагающая причина неравенства в средних школах содержится не в платности обучения, а в культурном и территориальном факторах расслоения населения [Свобода... 2007].

Тенденция четвертая. Школы разного типа практически прекратили заниматься профориентационной работой среди старшеклассников. Лишь около $1 \%$ респондентов указали, что их выбор вуза или специальности / направления подготовки был совершен по совету учителей. Основными агентами начальной профессиональной социализации выступают Интернет, родители и родственники, рекламные акции университетов [Чередниченко 2011].

Тенденция пятая. Современная российская школа не только утрачивает направленность на знание и умение размышлять, но и не занимается привитием и формированием таких фундаментальных для развития личности учащегося качеств, как трудолюбие, ответственное и обязательное отношение к своему

\footnotetext{
1 Условно мы разделили все школы в соответствии с их уставными документами на 3 категории: традиционная школа; школа определенного профиля с углубленным изучением отдельных предметов; школа нового типа (гимназия, лицей). К ним добавляется 4-я группа, в которую входят профессионально-технические колледжи, лицеи (ПТУ) и техникумы.
} 
гражданскому долгу - учебе. Несмотря на то что почти 59\% опрошенных студентов заявили о выборе специальности с целью удовлетворения собственных интересов и развития способностей, только каждый третий считает, что учится с полной отдачей сил. Около $6 \%$ скорее не учатся (лишь бы не отчислили) и откровенно бездельничают. Практически те же 59,1\% (в количественном отношении) респондентов относятся к овладению навыками будущей профессии без особого напряжения сил. А каждый пятый посещает аудито́рные занятия, чтобы встретиться, пообщаться с друзьями. Престиж, авторитет своих коллег по учебной группе более $30 \%$ студентов оценивают по их оригинальности, непохожести на других, почти $20 \%$ - по наличию широкого круга знакомств, нужных связей за пределами университета и по активной деятельности во внеучебное время (КВН, различные конкурсы, художественная самодеятельность и др.), свыше $10 \%$ - по имущественному положению, наличию дорогих и элитных вещей. При этом следует отметить, что около $60 \%$ учащихся вузов на 1-е место по влиянию в группе все-таки поставили успехи в учебе и наличие высоких моральных качеств.

В первую очередь обратим внимание на конфигурацию социальной идентичности студенческой молодежи вузов Ростовской обл. Респондентам был задан вопрос: «Как бы Вы ответили сами себе на вопрос: “Кто я такой?”» (в 2011 г. он был сформулирован: «Кем Вы себя ощущаете?»). Необходимо отметить, что у выпускников всех типов общеобразовательных учреждений на 1-м месте выделяется гражданская самоидентификация. Однако в большей степени она проявляется у студентов, окончивших традиционную среднюю школу $(63,9 \%)$, а также гимназию либо лицей $(57,1 \%)$. Среди выпускников профильных школ, ПТУ и техникумов показатель гражданской самоидентификации составляет $50 \%$. При этом наиболее существенные изменения по сравнению с данными предыдущих исследований наблюдаются только в отношении категории выпускников ПТУ и техникумов: в 2011 г. данный показатель у них составлял $40 \%$. Также у донских студентов в значительной степени выражена профессиональная идентичность. Однако она, наоборот, имеет большее значение для бывших учеников профильных школ и техникумов ( $41,6 \%$ и 41,3\% соответственно), нежели у молодых людей, окончивших обычную среднюю школу либо гимназию (32,3\% и 33,6\% соответственно). Это вполне объясняется тем, что молодые люди, имеющие профильное образование на момент поступления в вуз, обладают более четкими представлениями о собственной профессиональной принадлежности и определяют себя как специалиста в определенной области. Заметное место в иерархии идентичностей принадлежит также национальной (в пределах 16,5-20,4\%, в зависимости от типа оконченной школы) и территориальной $(11,9-5,2 \%)$ идентичностям.

Таким образом, очевидно, что вариации «мы-идентичности» в общей своей массе доминируют в сознании современных студентов над «я-идентичностью». «Мы-идентичность» развивается под влиянием самоопределения индивида посредством идентификации с той или иной общностью, группой [Элиас 2001]. «Я-идентичность» основана на осознании своей индивидуальности, уникальности. «Мы-идентичность» и «я-идентичность» не противоречат друг другу и выступают в качестве разных, но взаимно дополняющих аспектов личности. Однако та или иная форма идентичности может быть более значимой для самоопределения человека [Тишков, Бараш, Степанов 2017]. Как показали полученные данные, среди представителей донского студенчества, вне зависимости от типа оконченной школы, набирает обороты тенденция нарастания космополитических настроений: 37-39\% опрошенных, отвечая на вопрос: «Кто я такой?»-ответили бы: «Просто человек», а еще $11-12 \%$ считают 
себя гражданами мира. При этом в 2011 г. ответ «гражданин мира» указали только 5,4\% выпускников обычных средних школ и 7,5\% бывших лицеистов и гимназистов. Данная тенденция требует особого внимания, т.к. подобная позиция влечет за собой отрешенность от своего государства и общественнополитической жизни страны.

Как следует из полученных данных, большинство опрошенных, вне зависимости от типа оконченной школы, в той или иной степени считают себя патриотами своей страны: 1/3 опрошенных безусловно уверены в том, что могут назвать себя патриотами, а около $40 \%$ выбрали вариант ответа «скорее да». Абсолютно уверены в отсутствии у себя патриотических чувств примерно $4 \%$ среди бывших выпускников всех типов общеобразовательных учреждений. Вариант ответа «скорее нет» чаще остальных отмечали студенты, окончившие школу определенного профиля с углубленным изучением отдельных предметов $(13,7 \%)$. Также стоит заметить, что у студентов - выпускников учреждений профессионального образования был зафиксирован наибольший показатель затруднения с определением обладания чувством патриотизма $-21,7 \%$ так и не смогли дать однозначный ответ (тогда как среди других категорий респондентов значение затруднения с ответом не достигло отметки в 13\%).

Примечательно, что представители студенчества понимают, что патриотизм проявляется не только через любовь к родной стране (а именно этот аспект выпускники всех типов школ поставили на 1-е место), но и посредством реальных дел. 2-е и 3-е места в иерархии элементов, составляющих сущность патриотизма, по мнению молодежи, принадлежит работе, действиям во благо Родины, а также стремлению к изменению положения дел в стране для того, чтобы обеспечить ей достойное будущее. Наиболее активное деятельностное начало продемонстрировали бывшие ученики школ определенного профиля (среди них данные варианты ответа выбрали около 40\%).

Особого внимания заслуживает распределение мнения студентов о собственной гражданской принадлежности. Согласно полученным данным, гордость за свою гражданскую принадлежность испытывают в основном выпускники традиционных общеобразовательных учреждений - 73,1\%; среди бывших гимназистов и лицеистов, а также учеников школ определенного профиля данный показатель составляет около 64\%. А вот среди студентов, окончивших техникумы и ПТУ, только 57,8\% гордятся тем, что они россияне; вдобавок 2,2\% испытывают чувство стыда от данного факта (у остальных категорий респондентов этот показатель не превышает $0,3 \%$ ), а $15,6 \%$ не могут однозначно ответить на данный вопрос (против 9,1\% у выпускников СОШ). Это говорит о неопределенности и низком уровне отчетливости гражданской идентичности этой группы студентов.

Проанализируем отношение студентов вузов Ростовской обл. к соблюдению законов. Около половины студентов, вне зависимости от типа оконченной школы, полагают, что законы необходимо соблюдать, однако при этом надо ориентироваться на жизненные обстоятельства. Максимального значения данный показатель достигает у представителей профильных школ $-62,4 \%$; у данной категории респондентов отмечается и наивысшая приверженность принципу: «не стоит полагаться на закон, главное - справедливость» $-10,6 \%$. Наибольшую законопослушность демонстрируют выпускники традиционных средних школ - 24,9\% из них всегда следуют букве закона. Наиболее протестный характер поведения демонстрируют студенты постарше, уже получившие профессиональное образование в колледже, техникуме, училище. Они в 5 раз чаще остальных отмечали, что закон можно соблюдать тогда, когда он не мешает реализовывать личные интересы (15,2\%). Также среди них 6,5\% пола- 
гают, что закон можно беспрепятственно нарушать всегда (у остальных категорий данный показатель набрал не больше 1,8\%).

Для наиболее полного представления об отношении донских студентов к законам необходимо рассмотреть их мнение относительно допустимости отдельных правонарушений. Как следует из полученных данных, студенты более лояльно и приемлемо относятся к уклонению от службы в рядах вооруженных сил РФ: среди выпускников всех типов школ данный показатель превышает 20\%. При этом в отношении данного нарушения было зафиксировано больше всего затруднений с ответом у всех категорий респондентов. По всей вероятности, молодые люди еще не задумывались над решением данного вопроса, поскольку получили отсрочку от службы на время обучения в высшем учебном заведении.

И снова в отношении студентов, окончивших профессионально-технические училища и колледжи, есть основания для некоторого беспокойства. Именно представители данной категории чаще допускают возможность различных видов правонарушений, нежели бывшие ученики других типов образовательных учреждений. В наибольшей степени они считают допустимым уклонение от уплаты налогов - 26,1\% (тогда как у остальных категорий опрошенных данный показатель находится на уровне 9-12\%). Однако стоит отметить, что в отношении дачи взяток должностным лицам уровень допустимости в ответах выпускников учреждений профессионального образования и профильных школ оказался практически равным - 21,7\% и 21,3\% соответственно.

Рассматривая гражданскую и социальную активность молодых людей в стенах вуза и за его пределами, стоит обратиться прежде всего к соблюдению их прав как студентов. Как показали полученные данные, с правонарушениями в свой адрес сталкиваются около 1/10 студентов вне зависимости от типа оконченной ими школы. Чуть чаще нарушаются права гимназистов и лицеистов $(16,3 \%)$, а также выпускников школ определенного профиля (15\%). При этом около 1/4 респондентов не знают, нарушаются ли в вузе их права, что говорит о недостаточной правовой осведомленности студенчества.

Тем не менее необходимо отметить улучшение ситуации с нарушениями прав и интересов студентов за последнее десятилетие. Так, в 2006 г. 55,6\% выпускников традиционных средних школ не сталкивались с правонарушениями в стенах университета, в 2011 г. таковых стало уже 63,2\%, а в 2016 г. - 65,4\%. Схожий тренд наблюдается и в отношении бывших гимназистов и лицеистов. Однако среди студентов, окончивших техникумы и ПТУ, наблюдается обратная тенденция: частота случаев нарушения их прав увеличилась с 5,1\% в 2006 г. до $13 \%$ в 2016 г., а число тех, кто не сталкивался с правонарушениями, наоборот, уменьшилось с $71,8 \%$ до $58,7 \%$ соответственно. Однако уровень индифферентности в вопросе ознакомления со своими студенческими правами остался фактически неизменным (около 23\%), а у студентов - выпускников профильных школ и техникумов он даже вырос.

Возникает вполне закономерный вопрос: какие формы борьбы за свои права представители студенчества Ростовской обл. считают приемлемыми для себя? Как показали результаты проведенного исследования, студенты демонстрируют преимущественно спокойную реакцию на нарушение своих прав, выражающуюся либо в пассивности (около трети молодых людей, вне зависимости от типа оконченной школы, отдают предпочтение бездействию), либо в следовании формам борьбы, разрешенным законом: митинги, собрания, петиции и т.д. (34,8\% выпускников ПТУ и техникумов, 44-46\% остальных категорий). Прибегнуть к любым формам борьбы, в т.ч. гражданскому неповиновению, насильственному сопротивлению властям, готовы всего 3-5\% студентов традиционных и профильных школ, а также гимназий и лицеев. А вот среди 
выпускников техникумов такую готовность демонстрируют 17,4\%, что весьма настораживает (при этом по сравнению с 2006 г. данный показатель вырос на $10 \%$, тогда как у других категорий он, наоборот, уменьшился почти в 2 раза). Также обращает на себя внимание тот факт, что около $20 \%$ студентов, вне зависимости от типа оконченного общеобразовательного учреждения, не смогли с уверенностью заявить, каким образом они готовы отстаивать свои права. Допустим, действие или бездействие затруднившихся студентов будет зависеть напрямую от того, насколько сильно затронуты их интересы. Однако надо полагать, что у некоторых студентов данной группы затруднение с выбором способа борьбы связано с уже обозначенным незнанием своих прав. Стоит сказать, что по сравнению с данными 2006 и 2011 гг. увеличивается доля студентов, считающих оптимальными и позволительными легальные формы борьбы за свои права и интересы, равно как и уровень их пассивности (прежде всего, это выпускники гимназий, а также традиционных средних и профильных школ) [Социализация... 2014: 219-222].

Рассмотрим влияние типа оконченной школы на частоту участия студенческой молодежи в общественных и гражданских акциях. В ходе проведенного исследования представителям донского студенчества было предложено ответить на вопрос: «Участвовали ли Вы в каких-либо публичных, гражданских акциях в прошлом году?» Согласно полученным данным, чаще остальных участвовали в гражданских акциях студенты - выпускники традиционных школ, а также школ нового типа (гимназий, лицеев) $-27,1 \%$ и $26,6 \%$ соответственно. Более пассивная студенческая молодежь - это обладатели диплома профессионального образования.

Одним из главных способов проявления собственной гражданской позиции является участие в выборах различного уровня. Как показали полученные данные, около четверти опрошенных (25-28\%) стараются участвовать во всех проводимых избирательных кампаниях (кроме бывших гимназистов и лицеистов - среди них данный показатель составил 19,8\%). Примерно $20 \%$ пропускают выборы только по различным житейским обстоятельствам (болезнь, отъезд из города); чаще всего эту причину называли студенты, окончившие техникумы и ПТУ - 28,3\%. Можно заметить, что среди студентов, имеющих за плечами диплом о профессиональном образовании, оказалось меньше всего тех, кто пропустил выборы в связи с несовершеннолетием - 2,2\% (тогда как у остальных категорий опрошенных таковых оказалось около 14\%). Также заслуживает внимания тот факт, что принципиальная абсентеистская позиция характерна в большей степени для выпускников техникумов $(28,3 \%)$, профильных школ $(24,8 \%)$, а также гимназий и лицеев $(22,6 \%)$. Среди студентов, окончивших обычные школы, процент регулярного избегания выборов составил 18,5\%. Также позиция выборочного игнорирования электоральных кампаний в связи с недовольством особенностями их проведения характерна больше для гимназистов и лицеистов $-11,4 \%$.

В заключение можно сделать следующие выводы.

За период обучения в школе учащиеся не получают достаточного опыта общественной деятельности, характеризующей личность с активной гражданской позицией. В настоящее время актуализируется необходимость научного исследования развития и изменения гражданской активности современной вузовской молодежи. Социальное партнерство школы и вуза может создать благоприятные условия для формирования гражданской активности современной молодежи.

Опираясь на результаты социологических исследований 2006-2016 гг. в вузах Ростовской обл., мы установили, что гражданский и профессиональный виды 
социальной идентичности студенческой молодежи превалируют над национальной самоидентификацией. «Мы-идентичность» преобладает в сознании современных студентов Дона над «я-идентичностью». Педалирование своей гражданской самоидентификации более характерно для выпускников средних общеобразовательных школ, национально-этническая идентичность свойственна для выпускников лицеев, гимназий, профильных школ, акцент на профессиональную и семейную самоидентификацию отмечается у студентов, окончивших колледжи и технические училища. Более $60 \%$ студентов вузов Ростовской обл. не сталкиваются с нарушением и игнорированием своих прав в стенах вуза. Незнание и неясность своих прав отмечает почти каждый четвертый респондент. Около половины опрошенных студентов готовы отстаивать свои интересы, используя только легальные формы защиты. Установлен низкий уровень активности студентов вузов Ростовской обл. в общественной жизни своего вуза и города, что обусловлено незначительной осведомленностью о работе молодежных социальных организаций и объединений. Также были зафиксированы высокие показатели расплывчатости гражданской идентичности, протестности социального поведения, радикализации в борьбе за свои права и интересы, социальной и гражданской пассивности, а также допустимости совершения преступлений и правонарушений у отдельной группы респондентов - выпускников профессиональных училищ, техникумов и колледжей.

Статья подготовлена при поддержке внутреннего гранта ЮФУ № ВнГр-07/2017-27.

\section{Список литературы}

Свобода. Неравенство. Братство: Социологический портрет современной России (авт.-сост. Е.П. Добрынина; под общ. ред. М.К. Горшкова). 2007. М.: ИИК «Российская газета». 448 с.

Социализация и воспитание студенческой молодежи вузов Ростовской области (сравнительный анализ результатов исследований 2006, 2011 и 2013 годов): научно-методическая монография (под общ. ред. В.И. Филоненко; науч. ред. И.А. Гуськов). 2014. М.: Вузовская книга. 516 с.

Тишков В.А., Бараш Р.Э., Степанов В.В. 2017. Идентичность и жизненные стратегии студенчества в России. - Социс. Социологические исследования. № 8. C. 81-87.

Тощенко Ж.Т. 2011. Кентавр-проблема (Опыт философского и социологического анализа). М.: Новый хронограф. 536 с.

Филоненко В.И., Филоненко Ю.В., Скачкова Л.С., Мосиенко О.С. 2017. Стратегии социально-профессионального поведения студентов вузов (по материалам мониторинговых межрегиональных социологических исследований 2006-2016 гг.): монография (под общ. ред. Ю.В. Филоненко; науч. ред. В.И. Филоненко). Ростов н/Д; Таганрог: Изд-во ЮФУ. 198 с.

Чередниченко Г.А. 2011. Молодежь после получения среднего образования: образовательные и профессиональные траектории. - Вестник Института социологии. № 2. С. 67-86.

Элиас Н. 2001. Общество индивидов (пер. с нем. А. Круглова, А. Иванченко, А. Антоновского). М.: Праксис. 336 с. 
FILONENKO Victor Ivanovich, Dr.Sci. (Soc.), Professor of the Institute of Philosophy and Socio-political Sciences, Director of the Center for Socio-political Studies, Southern Federal University (room 131, bld. 3, 116 Dneprovsky Lane, Rostov-on-Don, Russia, 344065; vfilonenko@sfedu.ru)

MOSIENKO Ol'ga Sergeevna, Cand.Sci. (Soc.), Senior Lecturer at the Institute of Sociology and Regional Studies, Southern Federal University (160 Pushkinskaya St, Rostov-on-Don, Russia, 344006; mosienko.olga@mail.ru)

MAGRANOV Aleksei Sergeevich, Cand.Sci. (Soc.), Senior Researcher at the Center for Socio-political Studies, Southern Federal University (room 136, bld. 3, 116 Dneprovsky Lane, Rostov-on-Don, Russia, 344065; alex_daredevil@mail.ru)

\title{
THE ROLE OF SCHOOL IN THE FORMATION OF CIVIL ACTIVITY OF DON STUDENTS
}

Abstract. The article analyzes the civil and social activity of the youth. The authors show the importance of civil position in the structure of social identity and attitude to the observance of laws and the probability of committing offenses among students of Rostov Region depending on the type of finished school. The article bases on the results of the monitoring sociological research carried out in 2016. In addition, the paper suggests a comparative analysis with the data of studies conducted in 2006 and 2011 on a similar program to consider the dynamics of indicators of civil and social activity of students.

Keywords: school, civic activity, social activity, civic identity, students, socialization

ЗАЗИМКО Владислав Вячеславович - кандидат педагогических наук, доцент Московского пограничного института Федеральной службы безопасности РФ (129328, Россия, г. Москва, ул. М. Осташковская, 15; zvv@уапdex.ru)

\section{ИДЕОЛОГИЯ ПОСТМОДЕРНА И ПРОБЛЕМА ПАТРИОТИЧЕСКОГО ВОСПИТАНИЯ РОССИЙСКИХ КУРСАНТОВ}

\begin{abstract}
Аннотация. В статье доказывается, что навязываемая нам сегодня система ценностей и целей постмодерна связана с общей идеологией современного либерализма, направленного на ослабление нравственных начал в обществе. Это политическое направление, которое ставит любовь человека к себе на первый план, ведет к подрыву обороноспособности страны, препятствуя патриотическому воспитанию курсантов. Политика российской власти, направленная на сближение армейских учебных заведений и церкви, должна положительно отразиться на подавлении постмодерна и на усилении коллективистских принципов в жизни курсантов, а значит и на обороне границ.
\end{abstract}

Ключевые слова: воспитание, постмодерн, патриотизм, власть, Россия

\footnotetext{
A ктивное движение в сторону либеральной системы ценностей и целей, вызванное распадом Советского Союза, нанесло серьезный удар по воспитанию патриотизма, ставящего жертвенное чувство любви к своему отечеству и народу выше личной выгоды. Это чувство являлось важнейшей частью традиционно-исторической формы нашей национальной общности и ее религии. Взамен российскую молодежь стали приучать к мысли, что Родина не может и не должна быть главной социальной ценностью. Был выдвинут проект создания нового «мирового порядка» и «системы глобального уровня». В его основе лежал принцип индивидуализма, опирающийся на эгоистические рудименты человеческой психики и связанное с ними первоочередное стремление к материальной наживе, подавляющей нравственные начала.
} 